\title{
Development of China's urban leisure sports and existing Problems
}

\author{
Ma Liya \\ Zhejiang Pharmaceutical College \\ Ningbo,Zhejiang,315100, China
}

\begin{abstract}
In the continuous improvement of people's living standards today, the leisure sports is very important, this article make research of present situation on the development of city leisure sports in China, and summarize the effect of urban leisure sports, development status and development opportunities and bottlenecks and puts forward some measures and proposals to promote the city leisure sports development.
\end{abstract}

Keywords- City, leisure sports, residents

\section{INTRODUCTION}

After the twentieth century, the rapid development of science and technology, great changes occurred in human life. On the one hand, an increase in leisure time and increasingly rich material make necessary precondition and foundation for people to engage in leisure activities; on the other hand, diseases of modern civilization harassment of human health, forcing people to change their concept of life, began to seek a positive, healthy lifestyle. In the process of search for active leisure, sports, because of the participation of its own unique value, become popular leisure forms of choice. Leisure sport is to point to a way of life occurred in the spare time, which is based on certain physical activities, aiming at pursuing positive good physical and mental experience .Leisure Sports is one of the sports industry. When we examine leisure sports development, regional economic structure can not be divided from social development level of reality and its corresponding area. Especially in the south and north and the eastern and western regions of our country there are differences as well as regional comparative advantages of regional social and economic development. To this end, the Transition Period in China, to build recreational sports regional development model, and promote the healthy development of China's leisure sports has a special significance.

\section{THE ROLE OF LEISURE SPORTS}

\section{A. Leisure Sports can promote physical and mental health}

Modern society is increasingly competitive, either mental or physical labor, have increasing pressure on themselves, and people's nerves undergo a long period of high tension and anxiety, and patients with modern civilization are more and more. The study found that regular participation in recreational sports activities, help to improve the body's respiratory, digestive, urinary function, bones, muscles and cardiovascular system, promote the body's growth and development, improve the body's resistance to disease, and enhance the ability of the organism to adapt, and also can regulate repressed emotions, effectively resist depression, anxiety, confusion and other negative psychological factors, contribute to the prevention of the occurrence of mental illness; mold character in participation, maintain a healthy state of mind, so that the individual's enthusiasm, creativity and initiative can have a full play, enhance self-confidence, so that The personality can have healthy and harmonious development in a harmonious atmosphere.

\section{B. Leisure Sports help shape good spirit quality and spiritual home}

Leisure sports activities, in the process of completion of action will need their own will to overcome the difficulties caused by the sports load so as to nurture the people's will of calm, courageous, tenacious, aggressive, hard-working and so will quality be excellent. In addition, people must comply with the various rules of the game, to help train people to law-abiding, polite, caring, solidarity and bearing other excellent moral characters. Leisure sports and entertainment create a friendly, honest, cheerful and relaxed atmosphere. In the non-utilitarian atmosphere, people carry on emotional exchanges, enhance understanding, produce self-identify, build bridges of communication, and giving them more spiritual care.

\section{Leisure Sports promote social harmony and sustainable development}

Leisure Sports blend leisure, entertainment, games, health as a whole, when having participation in recreational sports, people get to know others of different identities, age, gender, mental and emotional exchanges make strangers become familiar, intimate, so that everyone create a warm, comfortable, friendly, family, life, work and social environments in the peaceful environment. It enables people to extricate themselves from the intense social competition, plunge into the casual sports activities to savor the happiness of being away from the crowd, and thus dilute the utilitarian sense when having interpersonal exchanges. While people 
involved in sports and leisure activities, this will reduce unhealthy participation opportunities for leisure activities such as gambling, alcoholis $\mathrm{m}$, superstition, and promote social harmony and stability.

\section{SITUATION ST ATUS ANALYSIS OF THE CIT Y'S LEISURE SPORTS}

\section{A. Rapid development of the coastal city of leisure sports}

There are data show that the current first start from the well-off coastal city residents who want to buy health, leisure methods like sports fitness awareness is growing, participation in leisure physical fitness has become a new fashion for today's coastal city residents. Wuxi, for example, since 1995, has built 21 National Fitness Projects, 250fitness point, levels of social sports guidance station, morning, evening exercises points reached to 600,906 public stadiums, 149 indoor stadium, more than 340 social Sport establishments, and investment amounting to more than 1,100 Yuan. More and more people get advantages from that. Expectancy of the average life of Wuxi citizens rise from 72.71 years old in 1995 to 76.98 years old in 2002, and has reached the average level of developed countries. Another example is the Pearl River Delta. 2002 Guangdong Province has invested more than 20 billion fund into stadium construction, there are also 290,000 square meters of National Fitness Project are under construction. Among them, there are three large-scale, well-equipped fitness center and five leisure sports fitness that each of them is more than 20,000 square meters. Former noble sport ---golf, has melted into the daily life, and the bowling, tennis, table tennis are beginning to gain popularity in the city and the countryside. In short, with the further development of the economy, coastal cities will have a significant role in the transmission, and gradually would spread to inland and remote areas; large-scale development is bound take place in the public.

\section{B. Rapid developments of leisure sports fitness tourism}

Since 1995, China began to implement a five-day work day, especially in 1999 the state has promulgated the three long holidays (the Spring Festival, May Day and National Day), and it has greatly stimulated the enthusiasm of urban residents in the case of recreation and tourism. In addition to the traditional view tour and leisure sports fitness, the characteristics of participation, ornamental, healthy and highly challenging and entertaining, meet the demand of urban residents, make them pursue music and enjoy a higher level of cultural needs. Recreational sports tourism market development having bright prospects. According to preliminary estimates of the Guangdong Provincial Tourism Bureau, 195 golf courses are built in the country, the Guangdong occupy 70 golf courses, if we make the effort to open up the golf market in Guangdong, next year it will at least attract about 10 million visitors to come outside Guangdong. The industry estimates, foreign tourist come to Guangdong to play and including the accommodation, transport, food, consumer' cost generally reached to a million, as projected a year, will bring more than 1 billion yuan in revenue. According to the data again: Ningbo make full use of the advantages of tourism resources, pay large attention to sports, make sports a brand to promote tourism and have made remarkable achievements. Ningbo has organized a celebrity football match Lokomotiv arena football league, the National Beach Volleyball Tour, national chess grandmaster tournament, golf tournament and other celebrities. Zhenhai Jiulong, Xiangshan marine fishing, the Silver Wind Creek Resort beach volleyball base, East Lake Qianqi Golf Course, Xiangshan Songlanshan national windsurfing training base, and overwater base, Ningbo Sports tourism base in Ningbo which cost 300 million yuan, have attracted a large number of domestic and foreign touris ts to visit the area, entertainment, le isure, fitness, so the leisure sports tourism is booming. In line with the 2001 China Sports Tour theme, Ningbo City, also arranged China Sports Tour series of events in 2001, the World Chinese cricket match, Youngor International Amateur Tennis Tournament, Ningbo International Chinese mahjong game, a large number of events such as the World Badminton Grand Prix have taken place in Ningbo so that sports and tourism promote each other, complement each other and become a new growth point of nationaleconomy in Ningbo.

\section{Infrastructure of city leisure sports fitness activities continue to strengthen}

In order to meet five days a week working system and market economy fast lane, on the one hand, China actively introducing interesting foreign entry port and fitness entertainment facilities, on the other hand, we stick to leisure sports fitness diversified, funny, and entertaining. All levels government and sports authorities increased the infrastructure construction of leisure sports activities and carry out creative leisure physical fitness services. Such as a fitness center, Shanghai Changzheng invested more than 32 million in more than 10,000 square feet of space to accommodate the 22 sports, there are people's familiar and favorite folk fitness programs, there are also rock climbing, kickboxing, skateboarding and other emerging projects; not only basketball, badminton, squash, swimming and other indoor and outdoor projects, there are also physical fitness stations, fitness counseling and other services, a set of fitness, recreation, leisure, health testing, scientific guidance are included in the model center. Currently, Shanghai is endeavoring to build a daily, weekend, festival (long) holiday leisure sports circles as one of the important activities of 2004-2010 measures. Weekends living area is mainly to give leisure and sports services, including the construction of public sports facilities, commercial sports facilities, and sports facilities and other diversified social public recreation sports fitness and entertainment service base. In addition, with economic development, in the design of new housing, real estate developers are willing to build recreational sports fitness facility in the overall plan. Like South Olympic Park in Guangzhou, Shanghai, Anda, Chongqing Olympic Park, through neighborhoods art gym, tennis courts, badminton courts, etc., we give full play to the idea: sports are just home front, life is like golf. 


\section{QUEST IONSIN THE CURRENT DEVELOPMENT OF CITY LEISURE SPORT S S}

A. Leisure sports industry in general is still very backward Leisure sports development of urban compared with Western countries, obviously late. Residents are not too familiar with the leisure sports knowledge, the government was busy leading sports development strategy, while ignoring the development of sports and leisure investment, resulting in its poor industrial development, inadequate infrastructure, and sports venues per capita area is less than $1 / 3$ of developed countries, and only the percent of U.S. 1/20. In the development of sports industry, there is also a serious imbalance in leisure. Businesses invested more focuses on aristocratic leisure sports, less of popular ones. All these show that China's urban leisure sports industry are backward, we should accelerate the pace of development of urban leisure sports and balance development of sports and fitness, then achieve great development undertakings .

\section{B. The unreasonable use and governing of leisure time by residents}

With the reform of the system of work, leisure time of urban residents has increased to at least 30 hours per week. However, the people govern the use of leisure time not enough scientifically. Many people's leisure time are spent at home watching TV or sleeping. The most prominent phenomenon is people who is 60 years or older watching television for more than four hours a day, some low-income households watching TV to an average of the amount of $1 / 3$ leisure time per day. And some non-incumbents leisure time is spent $2 / 3$ spent at home, the other part is used on a stroll consumption activities such substances, although occasionally there are some outdoor recreational activities, but the quality is not high. Most college students like to sleep in a dormitory or spend their le is ure time playing computer when they do not have class. Clearly, China's urban residents use leisure time unreas onably, most of them choose to spend at home, and the time for outdoor le isure activities are rarely used, even less are used in physicalactivity.

\section{Theory poor of Leisure Sports}

China's urban research of relevant domestic leisure sports, most focus only on commercial operation of existing public sports venues, and as to leisure sports city in terms of theoretical studies, there is no unified concept and a highly theoretical system, which is not conducive to guide urban leisure sports practice. Development of urban leisure sports adhere to the "people-oriented", but there is still a lack of systematic exploration of study sports about leisure patterns from a life-cycle perspective of people, namely the lack of focus on leisure sports on the significance of people at different stages of life as well as systematic thoughts and research of the features and limitations of the various stages of Leisure Sports features and research on important is sues such as limiting factors for the different life stages of leisure sports are also asked to contact the study but did not. In addition, from the perspective of a market economy system, in-depth study on China's leisure sports products and service system has not yet been reported. And we did not well learn from the advanced experience of Western countries, to develop systems meet China's national conditions, building, city leisure sports organization and management system with Chinese characteristics

\section{CONCLUSION}

In the leisure field of vision, we should start from a people-centered premise, give full play to the role of leisure sports, so while the material continues to develop, it can promote people's physical and mental health, improve the quality of spiritual life, and promote social harmony and sustainable development. Although the city still has many leisure and sports is sues to be addressed in development, but we should be balance all the things, and have comprehensive thinking, from all levels to explore all angles suitable for mass consumption, leisure sports, leisure sports to promote the development of the city, and ultimately to promote the development of leisure sports leisure sports development in rural areas. From the general direction, the development of social and economic plays a good role in promoting development in the le isure sports and prospects is optimistic. As public awareness of leisure sports continue to strengthen, urban leisure sports will continue to improve towards higher and better direction.

\section{REFERENCES}

[1] Wang Xudong, China's industrial strategy of sustainable development to select [D]. Jinan University, 2001.

[2] Fu Lixia. Leisure Shanghai Urban Development Evaluation Study [D]. , East China Normal University, 2012.

[3] Jiangke.Current Situation Shanghai urban residents participating in recreational sports activities and Countermeasures [D]. Shanghai Institute of Physical Education, 2013.

[4] Xie D Y. Present Situation of Chinese soil dynamics and problems [J]. Northwestern Seismological Journal,2007,01:94-95.

[5] Yu Jian, Sun Youzhi. Status quo of China's urban leisure sports, problems and countermeasures [J]. Shandong Institute of Physical Education, 2007,04:29-31.

[6] Cao Chen. Comparative Study of Leisure Sports Industry [D]. Capital University of Economics and Business, 2005.

[7] Li Xiafang.Situation and Development Strategies Jiangxi Province to carry out urban leisure sports[D]. Jiangxi Normal University, 2006.

[8] Xu Chen. Development of China's venture capital and problems [J]. Beijing Economic Management Personnel Institute,2000,02:12-15.

[9] Shi Wan Yong. Dingxi, Gansu current development of vegetable production facilities and problems [J]. Shenyang Agricultural University,2000,01:147-148. 